\title{
Rural and Remote Health

\section{ORIGINAL RESEARCH \\ Challenges to the provision of community aged care services across rural Australia: perceptions of service managers}

\author{
P Savy, J Warburton, S Hodgkin \\ La Trobe University Albury-Wodonga Campus, Wodonga, Victoria, Australia
}

Submitted: 17 June 2016; Revised: 9 January 2017, Accepted: 25 January 2017; Published: 31 March 2017

Savy P, Warburton J, Hodgkin S

Challenges to the provision of community aged care services across rural Australia: perceptions of service managers

Rural and Remote Health 17: 4059. (Online) 2017

Available: http://www.rrh.org.au

\section{A B S T R A C T}

Introduction: The Australian community aged care sector is facing a growing workforce crisis, particularly in rural and regional areas. Its predominantly female workforce is ageing, and recruiting younger, skilled workers is proving difficult. The service sector, too, is proving highly complex and diverse as a result of contemporary aged care service reforms as well as ongoing difficulties in providing services to the growing numbers of older people living in Australia's rural areas. Despite these multiple challenges, there is a gap in research that explores how rural aged care services manage their day-to-day requirements for skilled workers across the diverse service sector. To address this gap, this article reports on the experiences and perceptions of a small sample of service managers whose organisations represent this diversity, and who are accountable for care provision in regional and rural locations. In such areas, recruitment and skill needs are contoured by disproportionate aged populations, distance and reduced service availability.

Methods: Eleven service managers were interviewed as part of a larger project that examined the skill and training needs of community aged care workers within the Riverina, a rural region in New South Wales. Qualitative data drawn from semi-structured interviews were thematically analysed to identify the managers' individual needs for workers and skills in the context of location, service parameters and availability of other health and community services.

Results: Thematic analysis of the interview data elicited three themes: services, roles and skill deployment; older workers and gendered roles; and barriers to recruitment. The findings illustrate the complexities that characterise the community aged care sector as a whole and the impact of these on individual services located in regional and rural parts of Australia. The participants 
reported diverse needs for worker skills in keeping with the particular level of service they provide. Significantly, their varying perceptions and practices reflect their preference for older, female workers; their reluctance to take on younger workers is negatively skewed by a lack of capacity to compete for, recruit and retain such workers and to offer incentives in the form of enhanced roles and career development.

Conclusions: The findings highlight the conceptual ambiguities inherent in definitions of community aged care work as broadly skilled and uniformly sought across the sector. On the one hand, demands for more and better trained workers to meet growing client complexity locate care work as skilled. On the other, managers of narrowly defined service activities may rely on a diminishing workforce whose skills they downplay in gendered and lay terms. This contradiction corresponds with long-held conclusions about the gendered, exploitative reputation of care work, a characterisation discursively constructed by privileging the moral dimensions of the job over the technical skills required for it. Significantly, the findings raise questions about the capacity of services, as they are currently structured and differentiated, to reshape and redefine aged care work as a 'good job', one that holds appeal and tangible rewards for new and younger skilled workers.

Key words: Australia, community aged care, gendered work, regional and rural location, service managers, workers' skills, workforce shortfall.

\section{Introduction}

Demands for a skilled and sustainable aged care workforce in Australia are set to intensify. One conservative estimate suggests that the current workforce across residential and community care sectors will need to triple by $2050^{1}$. For the community aged care sector as a whole, the issue is exacerbated by an ageing and gendered worker profile; substantial attrition is expected over the next two decades given the median worker age of $50^{2}$. This sector, composed as it is of a wide range of service types and care levels, faces particular challenges in competing for workers, particularly younger skilled graduates, to care for an increasingly frail population of clients. And, in regional and rural areas, the need for skilled workers is intensified by local conditions such as higher concentrations of ageing populations, distance from service centres and, in some cases, reduced service scope and diversity ${ }^{3}$.

One well-documented barrier to recruitment across the aged care sector as a whole is its negative image as an exploitative industry characterised by 'dead-end' jobs and menial work ${ }^{4}$. A substantial body of work depicts aged care work as hidden and gendered, and workers as poorly remunerated ${ }^{4-9}$. The 'lot' of workers is linked to the often casual and insecure terms of employment and industrial powerlessness ${ }^{5}$. A lack of political will to address these issues is demonstrated in the current government's policy vacuum following its repeal of the Workforce Compact, an initiative that proposed improvements in remuneration for direct care workers ${ }^{\mathbf{1 0}}$. Community-based workers are further disempowered by the hidden, domestic location of their work and by the apparent similarity of tasks across formal and informal caregiving. The wide range of tasks that constitute community aged care from housework to elementary health care - leads to ambiguous definitions of workers' skills, particularly in the context of the distinctions between services and the care tasks provided. Skill definition is further obstructed by the takenfor-granted degree of emotion work that facilitates workers' relationships with clients and the persistent gendering of this central element of care work $^{6,11,12}$. The moral dimensions of care work, which rest on worker virtue and passivity, are discursively privileged over technical skill to counter justification for higher rates of $\mathrm{pay}^{13}$. Such exploitation is especially apparent in the case of low socioeconomic workers, including migrant and refugee women, whose employment opportunities are narrow ${ }^{7,14-17}$.

It is this aspect of formal caregiving that is the focus of the present article. The intent is to address gaps in the existing literature around existing rural service provision for 
community-based aged care. Specifically, the authors address the lack of enquiry into the structure and process of how care work is produced as skilled or unskilled at the level of care organisation and delivery, and specifically from the perspective of service managers. Thus, the research question being addressed here is 'How do rural aged care community service managers perceive and respond to the need for community aged care workers?'

\section{Gaps in research: the insights and needs of service managers}

There is relatively little literature describing the organisational and managerial perspective of aged care services and the issues faced. Australian contributions describe how community aged care services are encouraged to keep wages low to increase profit margins or, in the case of charitable organisations, to crosssubsidise other organisational activities ${ }^{5,8}$. This work emphasises the impact of tightly calculated government subsidies to these organisations and the wider political economy. This context and its effects are well described in terms of the rationalisation and privatisation of publicly owned services, shifts towards user pay philosophies, decentralised systems of wage bargaining, increasing casualisation and insecurity of work, decreasing opportunities for employee loyalty, and suppression of gender equity in the workplace $^{9,18,19}$. While the literature contains considerable comment on the implications of these economic and industrial orientations for workers, their workloads and the downgrading of the emotional dimensions of client relationships ${ }^{6,11}$, the implications for service managers tasked with providing high standards of care and maintaining the health and independence of elders living at home remain under-researched.

It is the contention of this article that the experience and views of managers can provide insights into solutions and assist in the refinement of strategies towards successful recruitment. For example, the widely accepted proposal that educational solutions will address recruitment issues by upgrading the skill base of workers across the sector and providing a broadly skilled and flexible workforce ${ }^{20}$ can be critically examined through the first-hand knowledge and practices of managers representing the variety of service types that educational programs must serve. In Australia, basic qualifications for aged care work are obtained via the vocational education training (VET) sector. Recent curricular changes to VET aged care courses include competencies for meeting health needs in the context of clients' increasing chronicity and comorbidities.

The research findings presented here are part of a larger project that focused on community care delivery and worker recruitment, retention and training in case study sites located across the large agricultural region of the south-west of New South Wales, Australia. In such locations, the needs for aged care services and a robust workforce are compounded by relatively large populations of ageing residents, their comparatively poor health, and the reduced availability of and proximity to healthcare services ${ }^{21}$.

\section{Methods}

The larger project of which this article is a part took a mixed methods approach that commenced with an extensive literature review. The aim of this review was to contextualise workforce and training issues and to develop a conceptual framework for the interview schedules and the analysis. The study was conducted in five case study sites across the Riverina region of southern New South Wales. These sites were selected to represent the diversity of service provision in the region, including services from a large regional town, as well as a number of smaller areas, which distribute services over a large geographic area.

The focus was on the practices and perspectives of a sample of 11 service managers who operated within the diverse and complex organisational structure of rural and regional community aged care services. The 11 participants, all women, occupied senior managerial roles. Their qualifications and background experience across a wide range of healthcare settings - including rural hospital management, acute inpatient care, accident and emergency, rehabilitation programs, infection control and worker training and assessment - equipped them with substantial knowledge of 
healthcare systems, direct patient care and personnel management. In their roles at the time of interview, these managers were responsible for the oversight, rostering and deployment of direct care workers. The diversity of both case study sites and organisational roles occupied by this small sample of managers strengthened the sampling frame. The sample of services represented here reflect the differing size, scope and location of such services that make up the complex arrangements and environments in which formal care activities are delivered in Australia (Table 1).

Semi-structured interviews were conducted focusing on five interrelated topics: workforce education and training; client care needs and practice; role enhancement; workforce needs and worker satisfaction; and issues, innovations and suggestions for the future. Interviews lasted approximately 1 hour and were conducted in person at the managers' workplaces, with the exception of one, which was conducted by telephone. Informed consent was obtained from each participant. The interview data were manually transcribed and coded within the framework of the interview schedule. Rigour was added to the study through the collaborative and reflexive approach to data collection and analysis, whereby all three authors took part in the interviews and participated in an iterative process of data analysis. Additional rigour was provided through an audit trail, as well as discussion of both process and findings across the larger project reference team.

Several pervasive themes were elicited that describe the managers' recruitment difficulties in terms of their distinct needs and local circumstances. These themes also provide for conceptual exploration of the tension between the wider discussion about workers' skills and educational needs and the idiosyncratic needs of the service managers.

\section{Ethics approval}

Ethics approval was provided by both La Trobe University (FHEC 13/241) and Greater Western Human Research Ethics Committee (LNR/14/GWAHS/52).

\section{Results}

The findings provide insights into the managers' individual workforce needs and their perspectives on worker skills in building a viable and responsive local service. The three broad themes elicited from the data in response to the research question include services, roles and skill deployment; older workers and gendered roles; and barriers to recruitment.

\section{Services, roles and skill deployment}

The managers' needs for skilled workers are shaped by the range of services they offer, their proximity to and relationship with other services, and their geographical locations. For example, managers of small rural services reported their need for broadly skilled workers to work across residential, inpatient and community care divisions of their service. Such flexible workers are necessary, costeffective elements in rural services:

$$
\begin{aligned}
& \text { We expect our staff to be much more generalist and to have a } \\
& \text { broader knowledge base - we need to operate from a lower } \\
& \text { base - we can't afford Registered Nurses. (manager 4) }
\end{aligned}
$$

In more narrowly defined services located in the larger towns and regional centres, workers' roles are defined according to the particular scope of care they provide. For example, services that provide post-acute nursing and transitional care require workers with clinical competencies and rehabilitation skills. Such workers may be brokered in from other general services to meet specific care plan needs. In contrast, the home care managers downplayed their need for skilled and ambitious graduates:

\footnotetext{
Someone graduating from TAFE [technical and further education] has got a set idea about what the job is - for example, they may state that they just want to do personal care and no housework. But $90 \%$ of the job is housework ... a percentage of workers will leave when they find this out. (manager 6)
} 
Table 1: Aged care in rural and regional Australia: description of sample services

\begin{tabular}{|c|c|c|c|}
\hline Service description & $\begin{array}{l}\text { No. of managers } \\
\text { interviewed }\end{array}$ & Location & $\begin{array}{l}\text { Principal care tasks of } \\
\text { community workers }\end{array}$ \\
\hline $\begin{array}{l}\text { Large organisation providing multiple service } \\
\text { divisions including community and day centre } \\
\text { services locally and in outlying rural areas }\end{array}$ & 1 & Large regional centre & $\begin{array}{l}\text { Personal care, housework, meal } \\
\text { preparation, transportation and } \\
\text { shopping, elementary health care, } \\
\text { medication management }\end{array}$ \\
\hline $\begin{array}{l}\text { Large organisation providing multiple service } \\
\text { divisions including residential, community, day } \\
\text { centre and transitional care }\end{array}$ & 2 & Large regional centre & $\begin{array}{l}\text { Personal care, housework, meal } \\
\text { preparation, shopping, elementary } \\
\text { health care, medication management, } \\
\text { rehabilitation }\end{array}$ \\
\hline Large home care service & 2 & Large regional centre & Home care, personal care \\
\hline $\begin{array}{l}\text { Small branch of large regional organisation providing } \\
\text { a mix of home care, personal care and nursing } \\
\text { services }\end{array}$ & 2 & Large regional centre & $\begin{array}{l}\text { Home care, personal care, post-acute } \\
\text { care, basic health care }\end{array}$ \\
\hline $\begin{array}{l}\text { Small branch of large regional organisation providing } \\
\text { mainly home care and personal care services }\end{array}$ & 1 & Rural town & $\begin{array}{l}\text { Home care, personal care, } \\
\text { transportation and shopping, home } \\
\text { respite care }\end{array}$ \\
\hline $\begin{array}{l}\text { Multipurpose centre providing a range of acute and } \\
\text { aged care services including residential and } \\
\text { community }\end{array}$ & 1 & Small rural town & $\begin{array}{l}\text { Home care, personal care, } \\
\text { transportation and shopping, } \\
\text { medication management, elementary } \\
\text { health care }\end{array}$ \\
\hline $\begin{array}{l}\text { Rural health service providing a range of acute and } \\
\text { aged care services including residential and } \\
\text { community }\end{array}$ & 1 & Rural town & $\begin{array}{l}\text { Home care, personal care, } \\
\text { elementary health care }\end{array}$ \\
\hline Large home care service & 1 & Rural town & Home care, personal care, shopping \\
\hline
\end{tabular}

Large services that provide a wide range of care activities require a pool of workers whose skills cover client needs for domestic, personal and basic health care. Workers with basic health and assessment skills for prompting medication use, taking blood pressure and dressing simple wounds add flexibility to the managers' capacity to meet the needs of the growing number of clients with higher care needs. Managers of such services base their deployment of workers on the individual specific needs of clients. One manager described the systematic grading of workers to 'match' them with clients:

We grade the care workers $-1,2$ and $3-2 s$ and $3 s$ do the personal care. It's on the level of assistance needed - everyone does personal care but some do more than others. (manager 6)

This kind of matching is critical given the reported complexity of care needs of community living elders. For example, specific observation and communications skills are required to maintain cognitive and physical functioning in the care of clients diagnosed with dementia. Such care may include the monitoring of psychotropic medications to ensure the correct administration and effects of these drugs. Workers may be hand-picked and trained to meet the growing demand of this level of care:

... we had a client on liquid Risperidol [an anti-psychotic drug]. We developed a client-specific competency and trained selected staff to do this. We excluded those workers who couldn't manage this task. (manager 1)

In all services, skills for observing and reporting changes in physical, social and psychological status are crucial for initiating interventions to prevent long term consequences such as loss of independence and the need for more intensive healthcare services. As manager 8 said, 'there's a lot of responsibility on workers to bring information back. One 
home care manager emphasised the significance of this information for other services such as district nursing and aged care and assessment teams whose professional workers are infrequent visitors:

... our girls are the eyes and ears for the other services ... Sometimes clients will not tell them about the changes and new problems but our staff will usually know and we have signed agreements from clients that allow us to discuss these matters with other agencies (M6).

This comment is congruent with rhetoric about the significance of direct care workers in the community for the health care system as whole. However, as the response by the same manager in the next section shows, these skills are minimised as the natural attributes of mature women, as an extension of the traditional female role.

\section{Older workers and gendered roles}

All the managers stated their preference for older workers, who they described as having 'life skills' and 'common sense':

\begin{abstract}
Most of the (older) workers have the skills to face whatever they come across - they are adaptable, they know when to feed things up to me. It's their experience and maturity - they come to the job with this. The younger the workers are the harder it is - [the skills] can be learned but it's not easy for them. (manager 9)
\end{abstract}

This view was taken further by the home care manager, who discounted the need for formal training as a prerequisite for employment in her service.

The ones who make the best care workers have never had education - they are experienced, mature women who are intimidated by education. Their families are off their hands, they have had lots of life experience ... the basics of going into someone's home, preparing and cooking meals, and organising how and when to do the chores are 'just natural'. (manager 6)
Older, female workers make up the core of the workforce in the study area. Many had worked in the same service for more than 10 years, providing a stable and dependable core of workers. However, this stability is offset by the ageing and approaching retirement of this group and their disinclination to take on further study and role responsibility. One manager described her older workers as lacking confidence and motivation and preferring to do domestic work rather than personal and healthcare tasks. The stamina of this group of ageing workers is also problematic. In one home care service, some $40 \%$ of workers were older than 60 years and, for many, the physical work associated with this role was becoming taxing. In manager 9's words, 'they are literally wearing out'. The managers described their strategies for assisting these workers to stay in the job and work up to pension age. For example, they rotate older workers through heavy and lighter assignments as a means of retaining longstanding, dependable staff.

\section{Barriers to recruitment}

Given the wider workforce issues and the ageing of their workers, the managers acknowledged the need to bring in 'new blood'. Yet, they all expressed their reluctance to employ young workers. One put this hesitation down to clients' complaints about younger workers who they see as lacking the skill to manage their time to complete all tasks:

Clients don't like the younger ones because of this - they have no life experience. They don't know where to start and the client sees this. (manager 5 )

Other managers described younger workers as unreliable:

[They are] averse to the accountability and the kind of work they are asked to do. (manager 9)

[Some young ones] just don't turn up - a couple just left the job and didn't bother to tell us. (manager 5)

This unreliability may be linked to an unpreparedness for the actualities of the work involved and the context of working 
alone in a client's home. In general, the managers agreed that the expectations of younger VET graduates were at odds with the roles and rewards offered by their services. Keen young graduates may find their roles disappointing, especially if housework forms the bulk of their work. The managers' view of young workers as unreliable and unsuited may also be linked to the limited induction and socialisation for recruits. They described how newly employed workers are buddied with an experienced worker for their first two shifts. After this, they must work alone, often in isolated rural environments.

Another possible reason for graduates' disappointment is that the services do not host students on placement practicums during their training. Hence, students do not develop an understanding of the work as it is structured and practised in the homes of aged clients. This gap in training is significant in that VET students and new graduates are more likely to be steered towards employment in residential rather than community care services. Moreover, as the managers noted, the approaches to care in these two settings are different. Manager 7 observed that graduates who have worked in residential care take a while to adjust from task orientation: 'They have to step back and let clients do for themselves'.

A major structural barrier to attracting and retaining suitable, younger workers concerns the managers' capacity to provide wage security. One manager acknowledged that younger workers quickly become dissatisfied with roster unpredictability and fluctuations in their pay packets. She explained that managers contract workers for a minimum number of hours in order to flexibly meet client demand and budgetary limits. In her experience, younger workers don't stay long in the job. She compared the roles she offered with better paid and less skilled jobs:

The money is not good enough - they can earn more stacking shelves [in the local supermarket]. (manager 1)

This manager described her inability to compete with other employers who offer better wages for less responsible jobs.
The best she could do in this regard was to reward workers with movie vouchers for good performance. However, she noted that tokenistic rewards are unlikely to satisfy younger workers, who she described as 'more materialistic' than her longstanding, older workers. Her reference to 'materialism' indicates that, for younger workers, the current balance between intrinsic and extrinsic rewards casts the job as exploitative. This incapacity to increase hourly rates of pay and wage security is, according to several managers, exacerbated by the change to a consumer-directed care model of government funding. These structural barriers to recruitment have increased the managers' reliance on and preferences for older workers. Their organisations have not, until now, established effective strategies for replacing these workers with younger and more ambitious workers. For younger graduates, the field of community aged care as it is currently structured offers relatively few opportunities for steady work, predictable wages and promotion.

\section{Discussion}

This article has demonstrated the complex structural issues facing those responsible for providing a suitably skilled and prepared aged care workforce across rural settings. The diversity and complexity of service provision is core to these findings. While the data presented here are derived from the accounts of a relatively small sample of local services and managers located across one large regional and rural area in Australia, they include participants from a diverse array of service types and provide findings that are remarkably consistent in terms of perceptions and experiences. Thus they provide important insights into the particular and challenging issues that bear on community care delivery in other nonmetropolitan locations. These data provide the basis for further studies to explore the restraints and opportunities relating to the recruitment of skilled, younger workers in a highly complex environment, including work that elicits the perceptions and experiences of workers themselves.

Overall, these insights suggest that solutions to workforce issues will need to account for the current complexity of 
service operations and the idiosyncratic needs constructed by location, size of ageing population and worker availability. The task of preparing and recruiting new workers is complicated by the diversity and scope of services in Australia, and the subsequent variety of direct care roles required by individual services. Perhaps unexpectedly, the managers' need for broadly skilled workers is clear cut in the case of the smallest, rural service. Like all multipurpose services catering for Australian rural localities, it relies on broadly skilled workers to meet the unique needs of its single but comprehensive health service ${ }^{22}$. In other locations, both large regional centres and small rural towns, where a variety of services co-exist and cooperate to maximise skill availability, the need for such workers is variously and ambivalently expressed by managers. The home care managers downplayed their need for VET graduates, who they regarded as overly prepared for the roles they offer. Even while emphasising their reliance on workers' capacity to detect early changes in clients' wellbeing, they underrated the necessary observation skills by defining them as the natural attributes of mature women. It follows that such narrowly defined services and care roles are unlikely to attract and retain younger graduates keen for breadth of practice and advancement.

The managers' strategies for retaining seasoned and flagging employees reflect the industry's longstanding reliance on older workers, many of whom entered the workforce with limited formal qualifications and few employment opportunities ${ }^{4}$. Over many decades, the tacit agreement between these women and the industry as a whole has produced an impression of natural fit between job, role and encumbent that is now no longer functional. These three constituents of what it means and takes to be a worker in the field of community aged care require genuine reconfiguration if younger and more highly skilled workers are to be recruited and retained. This focus on role reconfiguration is critical for two reasons. First, it is inevitable that the aged care workforce will remain the province of women into the forseeable future ${ }^{23}$. Second, for reasons of efficiency, their roles will continue to broaden by default as tasks are devolved from higher level and more costly health workers ${ }^{24}$. In other words, if roles are to be expanded to appeal to a more skilled, gendered workforce then the job in its construction via reward and career opportunities must support current recruitment initiatives.

The managers linked their current incapacity to compete for younger workers and vocationally trained graduates within the aged care sector and in other fields to several structural barriers. First, they lack the authority to offer regular contracts, upgrade pay and career opportunities. Second, they require newly employed graduates to work alone after a couple of buddied shifts. For new graduates, the task of becoming a competent community aged care worker is then a relatively solitary one, lacking the rich interpersonal and discursive materials available in team-based, institutional environments. The local culture ${ }^{25}$ afforded by these materials is significant and potentially encouraging for new recruits, who must negotiate challenges such as providing personal care for old and disabled bodies. The lack of such positive occupational socialisation within domiciliary services offers an alternative explanation for what the managers in this study describe as the transience, disinterest and unsuitability of younger workers. Third, the services represented in this study do not participate in student placement programs and so they forego opportunities for forming early and positive relationships with potential recruits.

Like all jobs, those in the aged care field carry images of the kinds of people who should occupy them ${ }^{26}$. Thus the construction and reputation of community aged care jobs are critical to the task of recruiting younger workers. Workers' status derives from their roles and the lay workplaces in which they carry out domestic duties. This status is reflected in the contractual arrangements that establish them as casual or part-time workers whose weekly hours of work fluctuate. It is equally reflected in classifications that locate their work at an intermediate service level or as relatively unskilled and repetitious ${ }^{5,19,23}$. In a competitive market, the industry's reliance on workers' intrinsic motivations to pursue community-based aged care work is, at best, risky. A consistent finding over time is that the subjective rewards that motivate care workers, such as intimacy, empathy and 
responsibility, provide a ready source of exploitation ${ }^{4,9,27}$. Notwithstanding the opportunities for exploitation, the intrinsic rewards associated with care work are significant sources of job satisfaction. As neo-liberal policies continue to intensify care work and widen the gap between its task and subjective elements, workers' sources of satisfaction are likely to diminish ${ }^{10,11}$. The relationship between personal satisfaction and extrinsic rewards in the form of secure hours of work, comparable wages and pathways for further credentialing and promotion provides a focus for re-shaping care work as a job. In other words, policy based on broadbased strategic planning is required to redress these issues and ensure that a sustainable and appropriately skilled workforce meets service and worker needs.

\section{Conclusions}

The question of who will care for the growing number of frail elders in their own homes, particularly in more isolated rural environments, highlights critical issues about the education and remuneration of community aged care workers. The promotion of upskilling and enhanced direct care roles is, on the face of it, a rational response. However, as the findings presented here suggest, a one-size-fits-all approach to ensuring an adequately skilled workforce overlooks the diversity and inconsistency of organisational needs across the service spectrum. Moreover, strategies that target only one strand of the problem, in this case, education of workers, do not address perennial issues and barriers to recruitment. The structural incapacities of managers to offer wages and career paths that build on skills and responsibilities deserve equal policy focus. The care of aged and frail citizens is necessarily both virtuous and skilled work. However, as findings from this study suggest, negative depictions and conditions are unlikely to attract younger workers who seek occupational enculturation without exploitation. The strength of the present study has been the focus on the views of existing managers in the field, and this now needs to be followed by further research from the perspective of younger workers, as well as care recipients, in order to contribute to a more tailored solution that more accurately meets both workforce and client needs.

\section{Acknowledgements}

This study was funded by the IRT Foundation, and we thank them for their financial support. We also thank the managers who participated so enthusiastically in this study.

\section{References}

1. Martin B. Good jobs, bad jobs? Understanding the quality of aged care jobs, and why it matters. Australian Journal of Social Issues 2007; 42(2): 183-197. https://doi.org/10.1111/j.1741-6612.2008. 00296.x

2. Department of Health and Ageing. Discussion paper: development of the aged care Workforce Compact. (Internet) 2012. Available: http:// www.agedcare.org.au/news/2012-news/workforce-compact (Accessed 9 March 2016).

3. King D, Mavromaras K, Wei Z, He B, Healy J, Macaitis K, Moskos M, Smith L. The aged care workforce: final report. (Internet) 2012. Available http://apo.org.au/research/aged-care-workforce2012-final-report (Accessed 30 July 2015).

4. Davis S, Bartlett H. Healthy ageing in rural Australia: issues and challenges. Australasian Journal of Ageing 2008; 27(2): 56-60. https://doi.org/10.1111/j.1741-6612.2008.00296.x

5. Palmer E, Eveline J. Sustaining low pay in aged care work. Gender, Work and Organization 2012; 19(3): 254-275. https://doi. $\operatorname{org} / 10.1111 /$ j.1468-0432.2010.00512.x

6. Hodgkin S, Warburton J, Savy P. Workforce crisis in residential aged care: insights from rural, older workers. Australian Journal of Public Administration. 2017; 76(1): 93-105. https://doi.org/ $10.1111 / 1467-8500.12204$ 
7. Bolton S, Wibberley G. Domiciliary care: the formal and informal labour process. Sociology 2014; 48(4): 682-697. https:// doi.org/10.1177/0038038513500098

8. Stacey C, Ayers L. Caught between love and money: the experiences of paid family caregivers. Qualitative Sociology 2012; 35: 47-64. https://doi.org/10.1007/s11133-011-9210-4

9. Ungerson C. Care, work and feeling. The Sociological Review 2006; 54(1): 188-203.

10. Somerville M. Becoming-worker: vocational training for workers in aged care. Journal of Vocational Education and Training 2006; 58(4): 471-481. https://doi.org/10.1080/ 13636820601005818

11. Hochschild AR. Global care chains and emotional surplus value. In: A Giddens, W Hutton (Eds). On the edge: globalization and the new millennium. London: Sage, 2000; 130-146.

12. Stacey C. Finding dignity in dirty work: the constraints and rewards of low-wage home care labour. Sociology of Health and Illness 2005; 27(6): 831-854. https://doi.org/10.1111/j.14679566.2005.00476.x

13. Colic-Pesker V, Tilbury F. Employment niches for recent refugees: segmented labour market in twenty-first century Australia. Journal of Refugee Studies 2006; 19(2): 203-229. https:// doi.org/10.1093/jrs/fej016

14. Doyle M, Timonen V. The different faces of care work: understanding the experiences of the multi-cultural care workforce. Ageing and Society 2009; 29: 337-350. https://doi.org/10.1017/ S0144686X08007708

15. Goel K, Penman J. Employment experiences of immigrant workers in aged care in regional South Australia. Rural and Remote Health (Internet) 2015; 15(1): 2639. Available: www.rrh.org.au (Accessed 31 March 2015).
16. Kaine S, Green J. Outing the silent partner: espousing the economic values that operate in not-for-profit organizations. Journal of Business Ethics 2013; 118(1): 215-225. https://doi.org/ $10.1007 / \mathrm{s} 10551-012-1583-0$

17. Connell RW. A really good husband. Work/life balance, equity and social change. Australian Journal of Social Issues 2005; 40(3): 369383. https://doi.org/10.1002/j.1839-4655.2005.tb00978.x

18. Husso M, Hirvonen H. Gendered agency and emotions in the field of care work. Gender, Work and Organization 2012; 19(1): 2951. https://doi.org/10.1111/j.1468-0432.2011.00565.x

19. Broadbent K. 'I'd rather work in a supermarket': privatisation of home care work in Japan. Work, Employment and Society 2014; 28(5): 702-717. https: //doi.org/10.1177/0950017013500113

20. Commonwealth of Australia. Inquiry into technical and further education in Australia. Community Services and Health Industry Skills Council submission to the House Standing Committee on Education and Employment. (Internet) 2014. Available: http:// www.voced.edu.au/content/ngv\%3A61809 (Accessed 8 March 2017).

21. Warburton J, Moore ML, Clune SJ, Hodgkin SP. Extrinsic and intrinsic factors impacting on the retention of older rural healthcare workers in the north Victorian public sector: a qualitative study. Rural and Remote Health (Internet) 2014; 14(3): 2721. Available: www.rrh.org.au (Accessed 10 September 2015).

22. Malone LM, Anderson JK. The right staffing mix for inpatient care in rural multi-purpose service health facilities. Rural and Remote Health (Internet) 2014; 14(4): 2881. Available www.rrh.org.au (Accessed 31 March 2015).

23. Gubrium J, Holstein J. Local cultures and service policy. In: J Gubrium, D Silverman (Eds). The politics of field research: sociology beyond enlightenment. London: Sage 1989; 94-112.

24. Acker J. Hierarchies, jobs, bodies: a theory of gendered organizations. Gender and Society 1990; 4(2): 139-158. https://doi. org $/ 10.1177 / 089124390004002002$ 


\section{Rural-and Remote-Health}

The International Electronic Journal of Rural and Remote Health Research, Education Practice and Policy

25. Meagher G. The challenge of the care workforce; recent trends and emerging problems. Australian Journal of Social Issues 2007; 42(2): 151-167. https://doi.org/10.1002/j.1839-4655.2007. tb00046.x

26. Jonsson I. Working hours and gender equality: examples from care work in the Swedish public sector. Gender, Work and Organization 2011; 18(5): 508-527. https://doi.org/10.1111/ j.1468-0432.2011.00563.x
27. Denton M, Brookman C, Zeytinoglu I, Plenderleith J, Barken R. Task shifting in the provision of home and social care in Ontario, Canada: implications for quality of care. Health and Social Care in the Community 2015; 23(5): 485-492. https://doi.org/10.1111/ hsc. 12168 